\section{Metastable Ion Decompositions in Methane and the Deuteromethanes}

\section{Ch. Ottinger}

Physikalisches Institut der Universität Freiburg

(Z. Naturforschg. 20 a, 1232-1234 [1965] ; received 20 August 1965)

The question whether metastable transitions in methane exist has been investigated several times ${ }^{1-3}$, and no evidence for the occurrence was found. The most extensive study by Dibeler and Rosenstock ${ }^{3}$ also included the deuterated methanes, in which the decomposition $\mathrm{CD}_{4}{ }^{+} \rightarrow \mathrm{CD}_{3}{ }^{+}+\mathrm{D}$ was found to be the only unimolecular one. Vestal ${ }^{4}$ made these findings plausible in terms of the quasiequilibrium theory.

We reinvestigated the problem using the previously described method ${ }^{5,6}$. The electron energy in the molecular beam was about $36 \mathrm{eV}$, except for $\mathrm{CHD}_{3}(30 \mathrm{eV})$ and for $\mathrm{CH}_{4}(29 \mathrm{eV})$. The ion energy in the condenser was normally $e U_{\mathrm{c}}=570 \mathrm{eV}$, which gives an energy of the ions in the drift space prior to decomposition of between 609 and $633 \mathrm{eV}$ depending on the species. The ion draw-out field was normally $E=200 \mathrm{~V} / \mathrm{cm}$. With these parameters

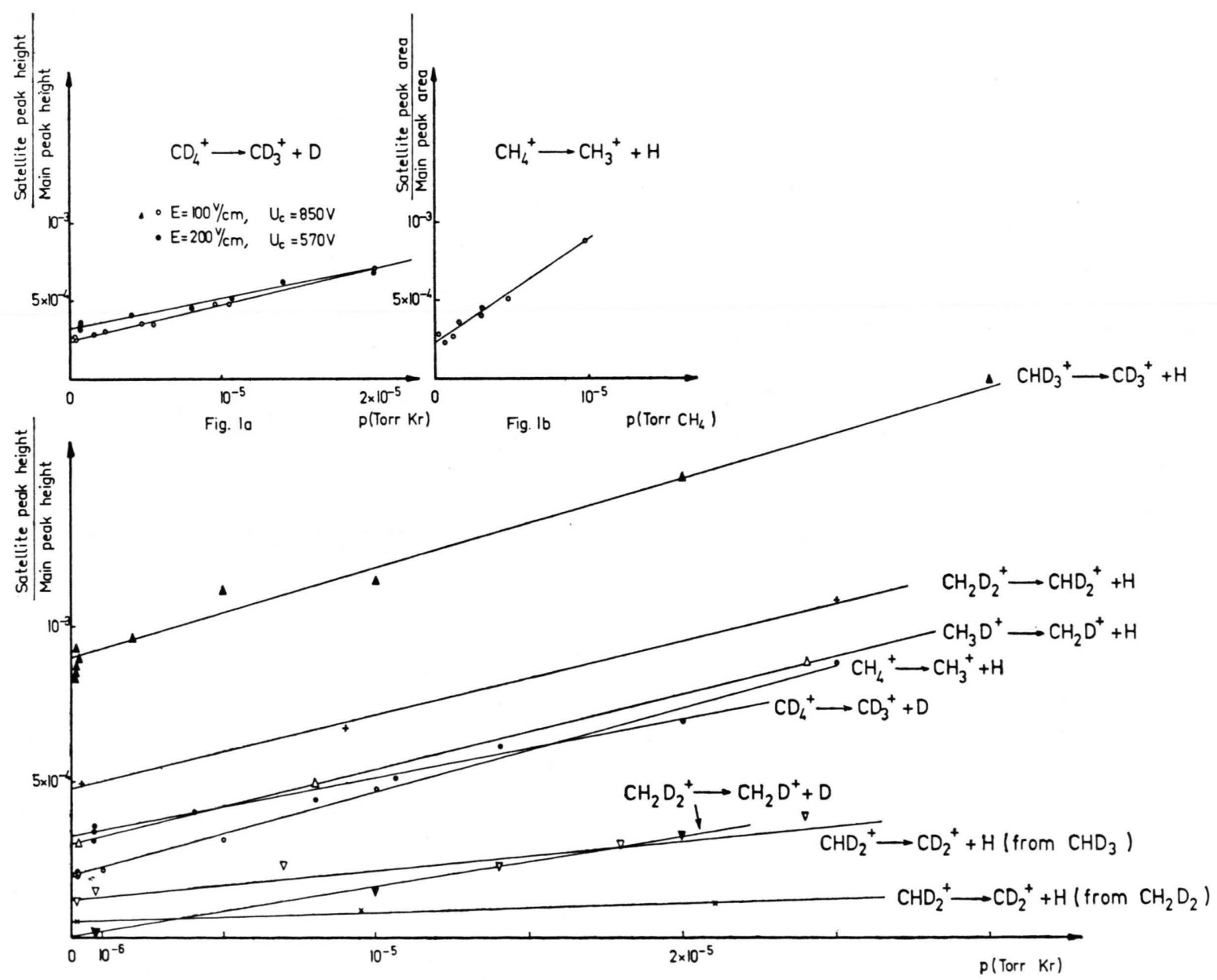

Fig. 1. Pressure dependence of fragmentations in flight.

1 C. E. Melton and H. M. Rosenstock, J. Chem. Phys. 26, 568 [1957].

2 D. P. Stevenson and D. O. Schissler, Actions Chimiques et Biologiques des Radiations, Masson et Cie., Paris 1961, p. 235.
3 V. H. Dibeler and H. M. Rosenstock, J. Chem. Phys. 39, 1326 [1963].

4 M. L. Vestal, J. Chem. Phys. 41, 3997 [1964].

5 O. Osberghaus and Ch. Ottinger, Phys. Letters 16, 121 [1965].

6 Ch. Otringer, Phys. Letters 17, 269 [1965]. 
the metastable "satellite peaks", consisting of ions formed between about 0.7 and $2.6 \mu$ s after ionization, were scanned by variation of the ion source potential. In order to reduce noise, the peak heights were determined with the ion source potential stationary by averaging over a period of approximately 5 minutes. Where at the lowest attainable pressure (usually $1.7-2 \cdot 10^{-7}$ torr) a satellite peak was found, the pressure was then raised by admitting krypton through a separate gas inlet into the apparatus. In Fig. 1 the satellite peak heights, normalized to the main peak heights of the same mass, are plotted versus the pressure. Ion loss through gas scattering, which amounted to $10 \%$ at $2 \cdot 10^{-5}$ torr, has been corrected for. The pressure was measured by a VeEco ionization gauge.

While the plots do not, and were not intended to, permit an accurate determination of cross-sections for collision-induced dissociations, they clearly show that the satellite peak heights do not tend to zero with decreasing pressure (with the exception of $\mathrm{CH}_{2} \mathrm{D}_{2}^{+} \rightarrow \mathrm{CH}_{2} \mathrm{D}^{+}+\mathrm{D}$, see below). The extrapolation to zero pressure leads to an intercept signifying the existence of true metastable decompositions in all five gases. The results are summarized in Table 1. Process 9 , which is presumably $\mathrm{CH}_{2} \mathrm{D}_{2}^{+} \rightarrow \mathrm{CH}_{2} \mathrm{D}^{+}+\mathrm{D}$, was measured as an example where the satellite peak could not be detected at the lowest pressure and only appeared at higher pressures. It is included in Fig. 1 and gives the only straight line extrapolating to zero.
A check was carried out in order to confirm that the metastable decompositions really occured in free flight and were not, for example, induced by glancing collisions with a fine mesh at the beginning of the field-free drift space. For this purpose the drift space potential was altered by applying a potential of $-180 \mathrm{~V}$ to electrodes surrounding the drift space like a tube, while the potentials of all electrodes that could be hit by the ions were kept constant. The $\mathrm{CH}_{4}{ }^{+} \rightarrow \mathrm{CH}_{3}{ }^{+}+\mathrm{H}$ satellite peak was thereby shifted by the expected amount $(\Delta m / m) \cdot 180$.

Satellite peak widths were measured for processes $1,4,8,12$, and 15 . They all showed very little broadening with respect to the main peaks, indicating very small fragmentation energies of the order of $0.005 \mathrm{eV}$ as calculated according to ${ }^{6}$. For $\mathrm{CD}_{4}{ }^{+} \rightarrow \mathrm{CD}_{3}{ }^{+}+\mathrm{D}$ a remarkably small broadening of only $30 \%$ on the mass scale was also reported in ${ }^{3}$. Since no trend in the ratios (satellite peak width) : (main peak width) was apparent, these ratios were averaged giving $1.27 \pm 0.05$. The intensities listed in Table 1, col. 5 are the intercepts from Fig. 1 multiplied by 1.27 , thus approximating the peak area ratio.

In col. 6 the metastable intensities have been normalized to the parent ion intensity $I_{\mathrm{p}}$ by multiplication of col. 5 by $I_{\mathrm{m}} / I_{\mathrm{p}}$ as taken from the ordinary mass spectrum. This provides a comparison with col. 7. It is interesting to note that in all cases where the apparent mass $m^{*}(\operatorname{col} .4)$ is well separated from an integral mass, there is agreement.

\begin{tabular}{|c|c|c|c|c|c|c|c|}
\hline \multirow[t]{2}{*}{$\begin{array}{c}1 \\
\text { No. }\end{array}$} & \multirow[t]{2}{*}{$\begin{array}{c}2 \\
\text { Gas }\end{array}$} & \multirow[t]{2}{*}{$\begin{array}{c}3 \\
m_{0}^{+} \rightarrow m^{+}+\Delta m\end{array}$} & \multirow[t]{2}{*}{$m^{4}$} & \multirow[t]{2}{*}{$\begin{array}{l}\mathbf{5} \\
\text { rel. metast. } \\
\text { intensity }\end{array}$} & \multicolumn{2}{|c|}{$\begin{array}{l}6 \\
6 \\
\text { "metast." intensity } \\
\text { normal. to } I_{p}=100\end{array}$} & \multirow[t]{2}{*}{$\begin{array}{c}8 \\
Q \\
\mathrm{~cm}^{2}\end{array}$} \\
\hline & & & & & $\begin{array}{l}\text { this } \\
\text { work }\end{array}$ & after $^{3} *$ & \\
\hline $\begin{array}{l}1 \\
2 \\
3\end{array}$ & $\mathrm{CH}_{4}$ & $\begin{array}{l}16^{+} \rightarrow 15^{+}+1 \\
16^{+} \rightarrow 14^{+}+2 \\
15^{+} \rightarrow 14^{+}+1\end{array}$ & $\begin{array}{l}14.06 \\
12.25 \\
13.08\end{array}$ & $\begin{array}{r}2.54 \cdot 10^{-4} \\
<2.5 \cdot 10^{-4} \\
<2.5 \cdot 10^{-4}\end{array}$ & $\begin{array}{r}0.019 \\
<0.001 \\
<0.001\end{array}$ & $\begin{array}{l}0.0009 \\
- \\
-\end{array}$ & $7.7 \cdot 10^{-17}$ \\
\hline $\begin{array}{l}4 \\
5 \\
6 \\
7\end{array}$ & $\mathrm{CH}_{3} \mathrm{D}$ & $\begin{array}{l}17^{+} \rightarrow 16^{+}+1 \\
17^{+} \rightarrow 15^{+}+2 \\
16^{+} \rightarrow 15^{+}+1 \\
16^{+} \rightarrow 14^{+}+2\end{array}$ & $\begin{array}{l}15.06 \\
13.23 \\
14.06 \\
12.25\end{array}$ & $\begin{array}{r}3.84 \cdot 10^{-4} \\
<7.6 \cdot 10^{-5} \\
<5.0 \cdot 10^{-5} \\
<3.0 \cdot 10^{-4}\end{array}$ & $\begin{array}{r}0.031 \\
<0.001 \\
<0.001 \\
<0.001\end{array}$ & $\begin{array}{l}0.003 \\
0.001 \\
0.001 \\
0.001\end{array}$ & $7.6 \cdot 10^{-17}$ \\
\hline $\begin{array}{r}8 \\
9 \\
10 \\
11\end{array}$ & $\mathrm{CH}_{2} \mathrm{D}_{2}$ & $\begin{array}{l}18^{+} \rightarrow 17^{+}+1 \\
18^{+} \rightarrow 16^{+}+2 \\
17^{+} \rightarrow 16^{+}+1 \\
16^{+} \rightarrow 15^{+}+1\end{array}$ & $\begin{array}{l}16.05 \\
14.22 \\
15.06 \\
14.06\end{array}$ & $\begin{aligned} 6.1 & \cdot 10^{-4} \\
<1.6 & \cdot 10^{-5} \\
6.7 & \cdot 10^{-5} \\
<2.0 & \cdot 10^{-4}\end{aligned}$ & $\begin{array}{c}0.033 \\
<0.0004 \\
0.0018 \\
<0.002\end{array}$ & $\begin{array}{l}0.003 \\
0.002 \\
0.003 \\
0.001\end{array}$ & $\begin{array}{l}5.1 \cdot 10^{-17} \\
1.6 \cdot 10^{-17} \\
5.8 \cdot 10^{-18}\end{array}$ \\
\hline $\begin{array}{l}12 \\
13 \\
14\end{array}$ & $\mathrm{CHD}_{3}$ & $\begin{array}{l}19^{+} \rightarrow 18^{+}+1 \\
19^{+} \rightarrow 17^{+}+2 \\
17^{+} \rightarrow 16^{+}+1\end{array}$ & $\begin{array}{l}17.05 \\
15.21 \\
15.06\end{array}$ & $\begin{array}{r}1.14 \cdot 10^{-3} \\
<1.5 \cdot 10^{-5} \\
1.55 \cdot 10^{-4}\end{array}$ & $\begin{array}{r}0.050 \\
<0.0007 \\
0.0006\end{array}$ & $\begin{array}{l}0.003 \\
0.004 \\
0.002\end{array}$ & $\begin{array}{l}5.0 \cdot 10^{-17} \\
3.2 \cdot 10^{-18}\end{array}$ \\
\hline $\begin{array}{l}15 \\
16\end{array}$ & $\mathrm{CD}_{4}$ & $\begin{array}{l}20^{+} \rightarrow 18^{+}+2 \\
20^{+} \rightarrow 16^{+}+4\end{array}$ & $\begin{array}{l}16.20 \\
12.80\end{array}$ & $\begin{array}{r}4.16 \cdot 10^{-4} \\
<6.0 \cdot 10^{-4}\end{array}$ & $\begin{array}{r}0.032 \\
<0.002\end{array}$ & $\begin{array}{c}0.027 \\
-\end{array}$ & $5.8 \cdot 10^{-17}$ \\
\hline
\end{tabular}

Table 1. Metastable Ions in Methane and the Deuteromethanes. * At particular pressures between 1.3 and $4.0 \cdot 10^{-7}$ torr, see ${ }^{3}$. 
These are the processes 5, 7, 9, 13 (no metastables found in either work) and 15 (found as metastable in both studies). All the discrepancies are associated with an $m^{*}$ close to integral masses (Nos. 1, 4, 8, $10,12,14)$. Now an examination of the satellite peak shape as a function of pressure shows a distinct broadening with increasing pressure, as shown in Fig. 2 for $\mathrm{CH}_{4}$, while the main peak did not change. $\mathrm{CD}_{4}$ was also checked for this, with the same result. This may indicate that lack of mass resolution in ${ }^{3}$ was the reason why the metastable components could not be detected, while the broad wings appearing at higher pressures were found.

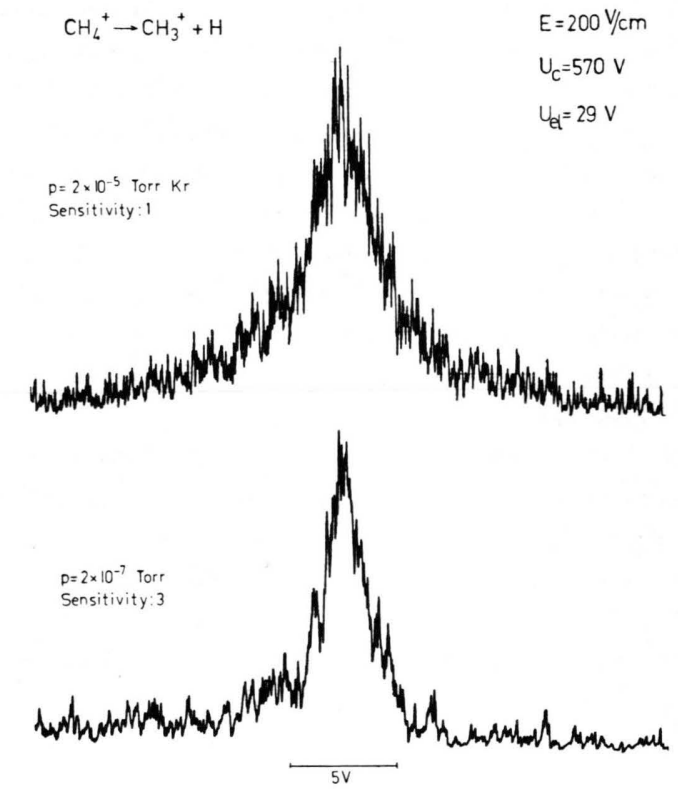

Fig. 2. Influence of pressure on satellite peak width.

The most interesting observation is, that except for process 15, the metastable transitions all consist of loss of $\mathrm{H}$ and never of $\mathrm{D}$. Also, the intensity change in the sequence $1-4-8-12-15$ seems significant: If there is only one $\mathrm{H}$ in the molecule, it is most likely to be lost in a metastable transition. This is also true for the secondary reactions 10 and 14 (both $\mathrm{CHD}_{2}^{+} \rightarrow \mathrm{CD}_{2}^{+}+\mathrm{H}$ ) as opposed to 3 $\left(\mathrm{CH}_{3}^{+} \rightarrow \mathrm{CH}_{2}^{+}+\mathrm{H}\right)$ and $6 \quad\left(\mathrm{CH}_{2} \mathrm{D}^{+} \rightarrow \mathrm{CHD}^{+}+\mathrm{H}\right)$ which could not be detected.

In order to check for an electron energy dependence, $U_{\mathrm{el}}$ was raised from $24 \mathrm{~V}$ to $54 \mathrm{~V}$ for pro- cess 1 . The metastable intensity remained the same within $10 \%$. The ion energy $e U_{\mathrm{c}}$ has a slight influence, as demonstrated in Fig. 1 a. This is due to a variation of the time of flight. The intensities in col. 5 were not corrected for different flight times, since, although the flight time in the field free region increases by $10 \%$ from process 1 to 15 , the entry into this region also occurs later for 15 than for 1 . A measurement of the decay function for process 15 in the manner of ${ }^{5}$ shows that this should lead to an intensity drop just cancelling the $10 \%$ increase.

For process 1 the pressure dependence was also measured admitting $\mathrm{CH}_{4}$ as target gas instead of $\mathrm{Kr}$. As now the "main peak" was no longer determined by the molecular beam profile, but was as broad as the total ionization region, its area, as well as that of the satellite peak, was measured with a planimeter. The plot of the area ratio versus pressure (Fig. $1 \mathrm{~b}$ ) gives an intercept of $2.3 \cdot 10^{-4}$ in good agreement with the relative intensity $2.54 \cdot 10^{-4}$ of Table 1. From the slope of the straight line in Fig. $\mathrm{l} \mathrm{b}$ an absolute cross section for $\mathrm{CH}_{4}{ }^{+}+\mathrm{CH}_{4} \rightarrow$ $\mathrm{CH}_{3}{ }^{+}+\mathrm{H}+\mathrm{CH}_{4}$ of $Q=9.4 \cdot 10^{-17} \mathrm{~cm}^{2}$ is calculated, in good agreement with $1.0 \cdot 10^{-16} \mathrm{~cm}^{2}$ stated in ${ }^{1}$ in spite of the different ion energy. $\mathrm{For} \mathrm{CH}_{4}{ }^{+}+\mathrm{Kr} \rightarrow$ $\mathrm{CH}_{3}{ }^{+}+\mathrm{H}+\mathrm{Kr}, Q$ was found by measuring the areas of the peaks in Fig. 2, normalizing them to the main peak areas at the respective pressures, and taking the difference. This gives the area increase caused by $2 \cdot 10^{-5}$ torr $\mathrm{Kr}$ and leads to $Q=7.7 \cdot 10^{-17} \mathrm{~cm}^{2}$.

For the other gases, cross sections can only be derived from Fig. 1 making the assumption, that the half-widths of the collision-induced components of their respective satellite peaks are the same as for $\mathrm{CH}_{4}$. One then gets the values of Table 1 , col. 8, after multiplication by $I_{\mathrm{m}} / I_{\mathrm{m}_{0}}$ from the mass spectrum in order to normalize to the precursor ion intensity. The cross sections are only considered accurate to within $\pm 50 \%$. It is seen that all cross sections are of the same order of magnitude except the ones for the two secondary reactions 10 and 14 which are considerably smaller.

I would like to express my gratitude to Prof. Dr. O. OsbergHAUs for making this work possible and for stimulating discussions, as well as to the Deutsche Forschungsgemeinschaft for financial support. 